\title{
Metal-organic framework [H2NMe2]3 [Tb(PDA)3] induces cytotoxic effects and changes DNA methylation-related gene expression in a human fibroblast cell line
}

\section{Leydi Maribel Carrilo-Cocom}

Universidad Autonoma de Yucatan Facultad de Ingeniería Quimica

\section{Lucia Juárez-Méndez}

Universidad Autonoma de Yucatan Facultad de Ingeniería Quimica

\section{Susana Rincon}

Tecnológico Nacional de México: Tecnologico de Merida José María Rivera-Villanueva

Universidad Veracruzana:Facultad de Ciencias Químicas

\section{Geovanny Iran Nic-Can}

CONACYT: Consejo Nacional de Ciencia y Tecnologia

Alejandro Zepeda ( $\square$ alejandro.zepeda@correo.uady.mx )

Universidad Autonoma de Yucatan https://orcid.org/0000-0002-0587-5039

\section{Research Article}

Keywords: cytotoxic, DNA methylation, human cells, metal organic framework

Posted Date: March 1st, 2022

DOI: https://doi.org/10.21203/rs.3.rs-396673/v2

License: (c) (i) This work is licensed under a Creative Commons Attribution 4.0 International License.

Read Full License 


\section{Abstract}

The lanthanide metal-organic frameworks (lanthanide MOFs) may be utilized for a variety of environmental and human health applications due to its luminescent properties and high thermal and water stability. However, the cytotoxic and epigenetic effects that these produce in human cells are not known. Therefore, we evaluated the cytotoxic effects, internalization and changes in DNA methylationassociated gene expression induced by exposing human fibroblast cells to a Terbium-based MOF (TbMOF). For this purpose, cells were exposed to six concentrations ( 0.05 to $1.6 \mathrm{mg} / \mathrm{mL}$ ) of $\left[\mathrm{H}_{2} \mathrm{NMe}_{2}\right]_{3}$ $\left[\mathrm{Tb}(\mathrm{PDA})_{3}\right]$ for $48 \mathrm{~h}$. SEM, Confocal microscopy and EDS analysis were performed. Cytotoxicity was determined with the Crystal violet and MTT assays. The results demonstrated the internalization of TbMOF at concentrations as low as $0.05 \mathrm{mg} / \mathrm{mL}$, as well as dose-dependent toxicity. Additionally, we detected significant changes in the gene expression levels of DNA methyltransferases and demethylases (important regulators of cell development) due to the presence of Tb-MOF, suggesting that Tb-MOF could generate epigenetic changes even at low concentrations. Results of our study may establish a foundation for future research attempting to develop and apply secure nanomaterials (e.g., MOFs) to minimize damage to the environment and human health.

\section{Introduction}

Recently, a new class of mesoporous materials known as metal-organic frameworks (MOFs) has attracted considerable attention. These nanometric materials are composed of organic ligands interspersed with metallic ions or clusters to form networks of nanopores with large surface area and novel properties (Sajid 2016).These characteristics have enabled the materials to be applied with great success in such applications as catalysis, gas storage, energy storage, magnets, drug delivery, optoelectronics, light emitting devices and sensors (Zhou et al. 2012; Gangu et al. 2016). In particular, the design, development, characterization and applications of new nanoscale MOFs have become topics of considerable interest in academic and industrial research (Pal and Bharadwaj 2016; Sajid 2016) because their properties are superior to those of conventional materials. In addition, these materials exhibit characteristics that suggest that they may have applications in biomedicine (Sajid 2016).

For example, nanoscale MOFs composed of lanthanide ions (Ln3+) and multitopic organic ligands have attracted the attention of researchers due to their luminescent properties, which are produced by their lanthanide aromatic complexes [Ln(PDA)3] (Lunstroot et al. 2009; Zhao et al. 2009; Pal and Bharadwaj 2016; Zhou et al. 2016). This luminescence has made these MOFs suitable for environmental monitoring (Wang et al. 2015; Liu et al. 2017; Huang et al. 2019) or fluorescence or luminescence bioassays (Dang et al. 2012; Fan et al. 2018). However, despite encouraging results obtained in applying MOFs in such areas as physics, chemistry and biology (Brame et al. 2011; Wuttke et al. 2017), there are no studies investigating the toxic effects of lanthanide MOFs on the environment or human health.

In general, it has been reported that the presence of the most common nanomaterials (NMs), such as $\mathrm{TiO} 2, \mathrm{SiO} 2, \mathrm{CeO} 2$, and Ag nanoparticles, cause cytotoxic and genotoxic effects in vitro on lung, embryonic 
kidney and liver cells, as well as on skin cells (fibroblasts and keratinocytes) and blood cells, such as macrophages (Wang et al. 2009; Gong et al. 2010; Sharma et al. 2012; Franchi et al. 2015).

Regarding other nanomaterials, such as MOFs, contradictory results have been obtained in several different cell lines regarding the toxicity that these materials induce. Lin et al. suggest that zinc-based MOFs have potential applications for human healthcare due to their characteristics and because they do not cause significant cytotoxic effects on human cells (Lin et al. 2016). In contrast, other studies have shown that MOFs are more toxic than noble metal nanoparticles and cause microbial cell death and damage human cells (Bashir et al. 2015a). Moreover, it has also been observed that the presence of ironbased MOFs in retinal pigmented epithelium human cells damages the plasmatic membrane and depolarizes the mitochondrial membrane due to oxidative stress (Bashir et al. 2015a). It is evident that different types of cells have been employed to test the toxicity generated by NMs according to the primary routes of exposure, such as ingestion, inhalation, blood circulation, and dermal penetration (Bashir et al. 2015b).

However, because the skin is a major route of exposure, there is interest in further characterizing the dermal absorption and toxicity produced by NMs, which is usually undertaken using skin cell models, such as keratinocytes and fibroblasts (De Matteis 2017). Specifically, there is a paucity of reports evaluating this skin penetration and toxicity caused by MOFs and there are none on the effects produced by lanthanide-based ones. Therefore, the evaluation on skin cells could help to identify the effects and routes of entry of these materials. In particular, it has been suggested that it is important to complement the studies of traditional toxicity pathways with epigenetic studies, since epigenetic changes can be triggered by exposure to NMs (Wang et al. 2018); based on the capacity of nanomaterials to produce free radicals within cells that can trigger to DNA modification or enzymatic disruption (Dusinska et al. 2017) .

DNA methylation, the best-characterized epigenetic modification typically associated with transcriptional repression (Rinaldi and Benitah 2015), is tightly regulated by sophisticated enzymes that act as writers and erasers on DNA. The first group consists of members of the DNA methyltransferase family, that is, DNMT1, DNMT3a, and DNMT3b, which add a methyl group at the carbon-5 position of cytosine to form 5-methylcytosine (5mC) (Plongthongkum et al. 2014). In contrast, demethylation is catalyzed mainly by ten-eleven translocation enzymes (TET1, TET2, and TET3) through $5 \mathrm{mC}$ oxidation to hydroxymethylcytosine (5-hmC), and derivates from this reaction to enable proper gene regulation, cell differentiation, genome integrity, and several biological processes (Rasmussen and Helin 2016).This epigenetic regulation represents a molecular link between environmental factors and the phenotypes that develop; therefore, disturbed epigenetic mechanisms, such as DNA methylation, may lead to the development of complex diseases, such as cancer (Brookes and Shi 2014). Thus, if NMs produce this type of epigenetic change, such as the DNA hypomethylation produced by SiO2 on human keratinocyte (Hacat) cells (Gong et al. 2010), these changes could have undesirable effects on human health. Unfortunately, studies on possible epigenetic changes produced by MOF are scarce to date. 
Recently, our group successfully synthesized three MOFs with lanthanide complexes, [H2NMe2]3 [Ln(III) (2,6-pyridinedicarboxylate)3] ( $\mathrm{Ln}=\mathrm{Sm}, \mathrm{Eu}, \mathrm{Tb})$, using a solvothermal method in the presence of a base and from inexpensive and readily available reactants, which might be used for diverse environmental and human health applications due to their luminescent properties and high thermal and water stability (Viveros-Andrade et al. 2017). However, the cytotoxic effects and changes in the expression of DNA methylation-related genes due to Terbium-based MOF (Tb-MOF) in human fibroblasts have not been elucidated to date. For this reason, in this work, we evaluated the cytotoxic effects, internalization and changes in DNA methylation-associated gene expression induced by the metal-organic framework [H2NMe2]3 [Tb(PDA)3] "Tb-MOF" on human fibroblast cells ( $\mathrm{hFB}$ ) to provide information relevant to the nanosecurity of Tb-MOF, which is important to minimize damage to the environment and human health.

\section{Materials And Methods}

\subsection{Materials}

All reagents used for the synthesis of Tb-MOF were purchased from Sigma-Aldrich Chemical Co., and reagent-grade solvents were dried and distilled according to procedures previously established in the literature (Viveros-Andrade et al. 2017). Single crystals were generated using spectroscopy-grade solvents. Melting points were measured in sealed capillaries on an IA-9100 model 10034137/01 Thermo Scientific electrothermal apparatus. Elemental analyses were performed on a PerkinElmer Series II CHNS/O model 2400 analyzer using cystine as a standard. IR spectra in the range of 4000 to $400 \mathrm{~cm}^{-1}$ were recorded in a PerkinElmer FT-IR Spectrum 400 spectrophotometer with a universal ATR sampling accessory at $298 \mathrm{~K}$. The crystal was mounted on glass fiber and studied with an Oxford Diffraction Gemini "A" diffractometer with a CCD area detector, with radiation source of $\lambda \mathrm{MoKa}=0.71073 \AA$ using graphite-monochromatized radiation.

\subsection{General MOF [H2NMe2]3[Tb(PDA)3] synthesis "Tb- MOF”}

The Tb-MOF was synthesized as previously reported (Viveros-Andrade et al. 2017). Briefly, a solution of terbium(III) nitrate pentahydrate $(69.6 \mathrm{mg}, 0.16 \mathrm{mmol})$ in $5 \mathrm{~mL}$ of deionized water was added dropwise to $5 \mathrm{~mL}$ of a methanol solution of 4,4'-bipyridine $(53.5 \mathrm{mg}, 0.32 \mathrm{mmol})$. The reaction mixture was refluxed for 90 min with stirring, after which a solution of pyridine-2,6-dicarboxylate acid $(0.32 \mathrm{mmol})$ in $5 \mathrm{~mL}$ of $\mathrm{N}, \mathrm{N}^{\prime}$-dimethylformamide (DMF) was slowly added at room temperature (Scheme 1 ). The reaction mixture was transferred into a Teflon-lined stainless-steel vessel. The solution was heated at $120^{\circ} \mathrm{C}$ for 4 days under autogenous pressure; the reaction was slowly cooled to room temperature and subsequently heated at $45^{\circ} \mathrm{C}$ for 2 days; colorless prism-shaped crystals formed from the reaction were filtered off, washed with distilled water, and vacuum-dried. The crystals were insoluble in water and common organic solvents (acetonitrile, methanol, DMF, acetone). Mp > 350 ${ }^{\circ} \mathrm{C}$. Yield: $60.9 \mathrm{mg}, 72 \%$. IR (ATR, $\left.\otimes \mathrm{cm}-1\right): 3543$ $(\mathrm{N}-\mathrm{H})$, 1467, $1431(\mathrm{C}=\mathrm{C})$ arom, $1600(\mathrm{C}=\mathrm{O}), 1572(\mathrm{C}=\mathrm{N}), 1387(\mathrm{C}-\mathrm{O}), 1371(\mathrm{C}-\mathrm{N}), 729(\mathrm{C}-\mathrm{H})$ arom. Anal. Calc. for $\mathrm{C}_{27} \mathrm{H}_{33} \mathrm{TbN}_{6} \mathrm{O}_{12}$ : C, 40.9; $\mathrm{H}, 4.2 ; \mathrm{N}, 10.6$. Found: $\mathrm{C}, 40.8 ; \mathrm{H}, 4.1 ; \mathrm{N}, 10.5 \%$. The X-ray 
diffraction of the compound was analyzed by Viveros-Andrade et al. (2017) and the compound had the same molecular structure as that previously reported here (Wang et al. 2015) (Supplementary Fig. 1).

\subsection{Cell line and culture}

Human fibroblast (hFB) from healthy breast tissue was provided by the Instituto Tecnológico y de Estudios Superiores de Monterrey, México. These cells were routinely grown in DMEM/F12 without phenol red medium (D2906, Sigma-Aldrich) supplemented with 10\% fetal bovine serum (BIO-S1650, Biowest) and $100 \mu \mathrm{g} / \mathrm{mL}-100 \mathrm{U} / \mathrm{mL}-0.25 \mu \mathrm{g} / \mathrm{mL}$ streptomycin, penicillin, and amphotericin B (ABL02, Caisson Laboratories), respectively, at $37^{\circ} \mathrm{C}$ in a humidified atmosphere with $5 \% \mathrm{CO} 2$. To be analyzed, cells were detached from cell culture flasks with $0.25 \%$ trypsin-EDTA (15090046, Invitrogen). Trypsin was neutralized with the same amount of complete culture medium. Concentration and viable cells were measured by the trypan blue exclusion method with the use of a hemocytometer.

\subsection{Nanomaterial stock solution and dilutions}

A stock solution of Tb-MOF at $3.2 \mathrm{mg} / \mathrm{mL}$ was prepared in Dulbecco's phosphate buffered saline (DPBS 1X, D5652, Sigma-Aldrich). Briefly, the material was pre-sterilized with UV irradiation for $30 \mathrm{~min}$ and weighed in a 50-mL sterile tube. Next, the compound was dissolved in sterile DPBS, and the solution was homogenized with a sonicator microtip probe at 130-Watt, $70 \%$ amplitude, for 15 min with a Cole-Parmer 130-Watt Ultrasonic Processor 4347 (UK).

Six concentrations $(0.05,0.1,0.2,0.4,0.8$ and $1.6 \mathrm{mg} / \mathrm{mL})$ were prepared through serial twofold dilution. For this step, the $1.6 \mathrm{mg} / \mathrm{mL}$ dilution was made by adding stock solution into complete 2X DMEM/F12 medium in a 1:1 proportion and then filtered with a $0.2 \mu \mathrm{m}$ syringe filter. The subsequent dilutions were made in $1 \mathrm{X}$ culture medium prepared by dissolving the $2 \mathrm{X}$ medium in DPBS. Stock solution and dilutions were prepared immediately before use.

\subsection{Cytotoxicity assay}

The cell density of hFB exposed and not exposed to Tb-MOF was determined for both, staining with Crystal violet (CV) and 3-(4,5-dimethyl-2-thiazolyl)-2,5-diphenyltetra-zolium bromide (MTT) tests. In the CV test, proteins and DNA of cells and the intensity of the color is proportional to the number of hypothetically viable adhered cells (Feoktistova et al. 2016). In the case of the MTT, this compound is reduced to a water-insoluble blue product by the mitochondrial dehydrogenases of living cells (Mosmann 1983). Briefly, for both assays, cells in the exponential phase of growth were inoculated in a flat-bottomed 96-well polystyrene-coated plate at $2 \times 104$ cells/well in $100 \mu \mathrm{L}$ of complete DMEM/F12 medium and allowed to attach for $24 \mathrm{~h}$. Then, the medium was removed and replaced with $200 \mu \mathrm{L}$ of diluted nanomaterial or only medium in triplicate. As a positive control known to be toxic to the cells, pure DMSO was used. The cells were incubated again for $48 \mathrm{~h}$. After incubation, CV staining was realized according to Feoktistova et al. (2016) with some modifications or addition of MTT according to the supplier's indications (Sigma Aldrich). For CV assay, the cells were washed twice in a gentle stream of tap water, and the plate was inverted and left to dry on filter paper. In each well, $50 \mu \mathrm{L}$ of $0.5 \%$ CV (C6158, Sigma- 
Aldrich) in methanol (34860, Sigma-Aldrich) was added, and the plate was incubated for 20 min at room temperature. After being washed four times in a stream of tap water, the plate was air-dried, and the remaining stain was dissolved with $200 \mu \mathrm{L}$ of methanol. For MTT test, after incubation, $20 \mathrm{uL}$ of MTT at $5 \mathrm{mg} / \mathrm{mL}$ (M2128, Sigma Aldrich) was added to each well, allowing it to incubate for $2.5 \mathrm{~h}$. At the end, the culture medium was removed and $100 \mathrm{uL}$ of DMSO was added. Absorbance was measured with a microplate reader (Multiskan FC Thermo Scientific) at $540 \mathrm{~nm}$ or $570 \mathrm{~nm}$ for CV or MTT assays, respectively. The percentage of cell density was calculated based on a comparison with control cells as (absorbance of exposed cells/absorbance of control cells) $\times 100$. The cytotoxic concentration 50 (IC50) was calculated by fitting the data to a sigmoidal dose-response equation using GraphPad Prism 7.0.

Three independent trials were performed. In addition, photographic records were acquired before staining to observe the morphological changes of the cells and again after staining to demonstrate the effects of Tb-MOF on adhesion, as reflected in cell density.

\subsection{Characterization of effects on human fibroblasts exposed to Tb-MOF}

\subsubsection{Cell preparation for microscopy}

The cells exposed to Tb-MOF were observed by field emission scanning electron microscopy (FESEM, JEOL JSM-7600F model) and confocal microscopy to observe the effect and the presence of nanoparticles on or within them. To this end, the cells were grown on ThermanoxTM coverslips (13 mm diameter). Previously, the slides were placed on a sterile Petri dish and exposed to UV irradiation for 30 min. Next, the slides were washed two times with DPBS and decontaminated by being incubated for $24 \mathrm{~h}$ in DPBS with $1 \%$ antibiotic-antimycotic solution. The slides were placed on the wells of 24-well plates and washed twice with DPBS. Cells were inoculated at $5 \times 104$ cell/well in $1 \mathrm{~mL}$ of culture medium and incubated for $24 \mathrm{~h}$. Next, the culture medium was removed, and dilutions of NMs were added to the wells $(1 \mathrm{~mL})$. The plates were incubated for $48 \mathrm{~h}$, and at the end of that time, the cells were washed twice with DPBS and examined under a microscope.

\subsubsection{Cell analysis by FESEM}

For the FESEM images, $3 \%$ glutaraldehyde in $0.1 \mathrm{M}$ sodium cacodylate buffer was added to the slides with cells, which were incubated at $4^{\circ} \mathrm{C}$ overnight. After incubation, the slides were washed two times with DPBS, and the samples were dehydrated in increasing concentrations of ethanol (50,70, 90 and 100\%) for 15 min each time. At the end of dehydration, the samples were placed in a sample holder, which was soaked in ethanol. Next, the sample holder was submitted to a process of critical point drying with liquid CO2 (equipment Quorum K850 model) for $1 \mathrm{~h}$. Later, the samples were fixed on aluminum stubs and were subsequently coated with a layer of gold-palladium (60:40\% each) through a sputtering coater process (equipment Quorum Q150R ES model). Finally, the cells were observed using FESEM. The images were taken by a LABE detector with back-scattered electrons under high vacuum at 10 or $15 \mathrm{kV}$ of voltage with a working distance of approximately $12 \mathrm{~mm}$ and magnifications of $150 \mathrm{X}$ and 2000X. Linear energy 
dispersive spectroscopy (EDS) analysis was performed to identify the presence of nanoparticles in a specific area with an OXFORD-INCA detector.

\subsubsection{Cell imaging by confocal microscopy}

To evaluate the presence of Tb-MOF in the cells, based on its autofluorescence, the hFB cells were grown on ThermanoxTM coverslips and exposed to $0.05,0.2$ and $1.6 \mathrm{mg} / \mathrm{mL}$ of nanomaterial for $48 \mathrm{~h}$, as previously described. Subsequently, the cells were washed three times with PBS to remove any nanomaterial that could remain on the cell surface and then these were fixed for 20 min at room temperature with $4 \%$ paraformaldehyde in DPBS, followed by two washes with DPBS. The fluorescence properties of the Tb-MOF in the samples were observed upon excitation at 330 and $490 \mathrm{~nm}$ accordingly to excitation spectra reported in Viveros-Andrade et al. (2017) by using a confocal laser scanning microscope (Olympus, FV100 SW). The images were acquired and analyzed by using FV10 ASW 3.1 viewer software (Olympus). As a reference, cell samples on slides were counterstained with DAPI mounting medium $(\mathrm{H}-1200$, Vectashield $($ ) $)$ according to the manufacturer's instructions, and the staining signal was detected using an excitation wavelength of $405 \mathrm{~nm}$.

\subsection{RNA isolation and quantitative reverse transcriptase- polymerase chain reaction (qPCR)}

The cells exposed to the concentrations of Tb-MOF producing the least toxic effect were analyzed to identify changes in the expression of DNA methyltransferases and demethylases encoded by DNMT (DNMT1, DNMT3a, DNMT3b) and TET (TET1, TET2 and TET3), respectively. Cells were inoculated in a 24well polystyrene-coated plate at $5 \times 104$ cells/well in $1 \mathrm{~mL}$ of medium and incubated for $24 \mathrm{~h}$. After incubation, cells were exposed or not (as a control) to three concentrations of Tb-MOF $(0.05,0.1$ and 0.2 $\mathrm{mg} / \mathrm{mL}$ ) and were incubated for $48 \mathrm{~h}$. Thereafter, the cells were washed (twice) with $1 \mathrm{~mL}$ of DPBS $1 \mathrm{X}$ and trypsinized with $0.30 \mathrm{~mL}$ of $0.25 \%$ trypsin-EDTA for 5 min. Subsequently, trypsin was neutralized by the addition of $0.30 \mathrm{~mL}$ of growth medium (DMEM/F12), and the cells were collected. The tube was centrifuged at $1000 \mathrm{rpm}$ for $5 \mathrm{~min}$, and the pellet was resuspended in $1 \mathrm{~mL}$ of DPBS. The cells were again centrifuged at $12,000 \mathrm{~g}$ for $5 \mathrm{~min}$, and the pellet was employed to extract and purify RNA. Briefly, total RNA was isolated using the Direct-zol RNA miniprep kit (R2051, Zymo Research) according to the manufacturer's protocol. RNA purity and quantification was carried out using a NanoDrop instrument. Reverse transcription reactions were performed using one microgram of RNA using the SuperScript III first-strand synthesis system (18080051, Invitrogen) following the manufacturer's instructions. To evaluate the messenger RNA expression of DNA demethylases and methyltransferases, quantitative RTPCR (qPCR) was performed in triplicate using iTaq Universal SYBR Green Supermix (1725120,BIO-RAD) in

an Eco Real-time PCR System (Illumina) and analyzed using EcoStudy Software (Illumina). Changes in gene expression were calculated relative to 18S rRNA using the 2- $\triangle \triangle C T$ method (Livak and Schmittgen 2001). The primers used for $q P C R$ analysis are listed in Supplementary Table 1.

\subsection{Statistical analyses}


CV and MTT tests were performed in three independent trials with at least three replicates per sample. Data of cell viability and relative expression level were statistically analyzed through parametric one-way ANOVA and Tukey's HSD post hoc test for each mean comparison. Statistical analysis and graphics were analyzed using GraphPad Prism 7.0 software. The data were plotted as the mean \pm standard deviation.

\section{Results}

\subsection{Effects of Tb-MOF on cell density}

To determine the cytotoxic effects of Tb-MOF, hFB cells were exposed or not (for the control) to different concentrations of Tb-MOF for $48 \mathrm{~h}$. Also, cells were exposed to medium with DMSO, as control of cell death. After exposure, the effects on cell morphology were visible starting at a concentration of 0.4 $\mathrm{mg} / \mathrm{mL}$, from which a percentage of the cells shrank and exhibited a rounded morphology (Supplementary Fig. 2). In addition, a dose-related reduction in cell density was also observed when the cells were stained with CV (Fig. 1). Control with DMSO effectively induced the total detachment of the cells, so these samples could not be stained (data not shown). In general, the results indicate that TbMOF induces the loss of adhesion capacity to the substrate and, finally, cell viability. Although the effects of Tb-MOF on cell morphology could only be visualized with optical microscopy starting at the concentration of $0.4 \mathrm{mg} / \mathrm{mL}$, the statistical analysis of the data obtained through the CV and MTT assays showed a dose-dependent response, with significant differences $(p<0.05)$ being observed in percentages of cell density with respect to the control at all concentrations (Fig. 2). Thus, the results obtained with these assays suggest that the density of the cells exposed to $0.05 \mathrm{mg} / \mathrm{mL}$ Tb-MOF is different from that of the control and that from the concentration of $0.8 \mathrm{mg} / \mathrm{mL}$ Tb-MOF, the cell density drops to less than $70 \%$ (Fig. 2). Similarly, it was possible to determine the inhibitory concentration $50 \%$ (IC50) by fitting a sigmoidal dose-response curve. The resulting average was IC50 $=0.260 \pm 0.012 \mathrm{mg} / \mathrm{mL}$ and IC50 $=0.384 \pm 0.087 \mathrm{mg} / \mathrm{mL}$ for CV and MTT, respectively. We present toxicity assessment by both methods because deposition and intracellular aggregation have been shown to disrupt light across spectral regions, which could affect the result of the crystal violet test. Likewise, some nanomaterials have been reported to interfere with the MTT assay by interfering with the compound or with the enzymatic activity of cells (Abe et al. 2018). In this study, only cells exposed to the highest concentration $(1.6 \mathrm{mg} / \mathrm{mL})$ showed a significant difference between assays but both significantly reducing cell viability. Therefore, these results indicated that fibroblast cells are damaged by exposure to Tb-MOF.

\subsection{Cell interaction with Tb-MOF}

To evaluate the cell interaction of Tb-MOF, hFB cells were exposed to the lowest $(0.05 \mathrm{mg} / \mathrm{mL})$ and highest $(1.6 \mathrm{mg} / \mathrm{mL})$ concentrations of Tb-MOF for $48 \mathrm{~h}$ (Fig. 3). In both cases, the presence of Tb-MOF was observed, and the clusters of nanomaterial could be clearly distinguished over cells exposed to 1.6 $\mathrm{mg} / \mathrm{mL}$, where MOF also induced a contraction of the cellular membrane (Fig. 3c). To determine whether the negative effects on cell morphology were due to Tb-MOF internalization within the cells, we carried out FESEM-EDS analysis. This analysis demonstrated the presence of terbium within the cells at 
concentrations as low as $0.05 \mathrm{mg} / \mathrm{mL}$ of Tb-MOF (Fig. 3d). However, since internalization could take place through damaged membranes, visualization by confocal microscopy was also performed.

Consistent with the EDS analysis, we noted that Tb-MOF photoluminescent signals were detected in the cell clusters exposed to both 0.05 and $1.6 \mathrm{mg} / \mathrm{mL}$ MOF (Fig. 4) by using a wavelength of 330 and 490 $\mathrm{nm}$. The results showed full nanoparticle internalization within the cells, particularly in the cytoplasmic region when the cells were exposed to a higher concentration (1.6 mg/mL) of Tb-MOF (Fig. 4).

\subsection{Gene expression patterns of DNA methylation-related genes in hFB cells exposed to Tb-MOF.}

DNA methylation, a well-established epigenetic mark, is widely involved in the control of gene transcription and cellular phenotypic changes, as well as genome stability. Therefore, in this study we evaluated the gene expression profile of DNMTs (DNMT1, DNMT3A, DNMT3B) and TETs (TET1, TET2 and $T E T 3)$ on DNA in hFB cells in response to treatment with three different concentrations of Tb-MOF $(0.05$, 0.1 and $0.2 \mathrm{mg} / \mathrm{mL}$ ) after $48 \mathrm{~h}$ of exposure. In this regard our results show that Tb-MOF affected the expression of DNMTs (Fig. 5A). For instance, the expression level of DNMT1 was only downregulated at $0.05 \mathrm{mg} / \mathrm{mL}$, while the expression levels of $D N M T 3 B$ were downregulated at all Tb-MOF concentrations. In contrast, all concentrations increased DNMT3A expression levels respect to the control. Additionally, because 5-mC can be oxidized to 5-hydroxymethylcytosine $(5 \mathrm{hmC})$ as part of a pathway to reverse DNA methylation, we further determined the expression profile of the TET genes. Treating hFB with Tb-MOF for $48 \mathrm{~h}$ induced upregulation of TETs genes in all treatments (Fig. 5B). Taken together, these results suggest that even at concentrations at which the compound maintains a toxicity below $30 \%$, exposure to this material induces an imbalance in DNA methylation patterns, since the expression levels of both DNMT and TET are affected by Tb-MOF exposure.

\section{Discussion}

Recently there is a growing interest in determining the effects of NMs in the innermost layers of the skin (Wang et al. 2018). such as the dermis, which is mainly composed of fibroblasts. For this reason and because the toxic potential of Tb-MOF is not yet known, in this work, a first approach is presented on the toxic effect of a Tb-MOF at the cellular and epigenetic level in hFB cells. In this study, cellular toxicity in hFB was observed after treatment with 0.05 to $1.6 \mathrm{mg} / \mathrm{mL}$ Tb-MOF, exhibiting a dose-dependent response. Thus, the lowest $(12.91 \%)$ and the highest $(76.71 \%)$ inhibitions of cell viability were obtained with $0.05 \mathrm{mg} / \mathrm{mL}$ and $1.6 \mathrm{mg} / \mathrm{mL}$, respectively. Similar results have been reported regarding the negative effect exerted on the viability of some human cancerous and healthy cell lines by another type of NMs based on Tb. For instance, in cancer cell lines, a study reported a decrease of approximately $10 \%$ in the viability of HeLa cells exposed to $0.1 \mathrm{mg} / \mathrm{mL}$ Eu3+-TbPO4 nanoparticles for $72 \mathrm{~h}$ (Di et al. 2011).

Similarly, MG-63 and Saos-2 osteosarcoma cells exposed to Tb203 $(0.001 \mathrm{mg} / \mathrm{mL})$ nanoparticles for 48 $\mathrm{h}$ had a $50 \%$ reduction in cell viability. The authors demonstrated a significant increase in the level of intracellular reactive oxygen species (ROS), which they suggest could be related to cytotoxicity (Iram et al. 
2016). Similar results were also reported by Setyawati et al. (2013) who observed a viability reduction of $40 \%$ in human skin fibroblasts in the presence of $0.75 \mathrm{mg} / \mathrm{mL}$ Tb-Gd2O3 nanoparticles after $24 \mathrm{~h}$ of exposure, suggesting that metal oxide nanoparticles could increase the mechanisms of oxidative stress and induce DNA damage and apoptosis. Our study shows the cytotoxic effect of Tb-MOF on hFB, nevertheless, if the reduction of cell viability is due to metal producing the generation of ROS and DNA damage, as proposed by some authors (Setyawati et al. 2013; Iram et al. 2016) it should still be evaluated.

On the other hand, we determined an IC50 of Tb-MOF between $0.260 \pm 0.012 \mathrm{mg} / \mathrm{mL}$ (Tb concentration of $0.052 \mathrm{mg} / \mathrm{mL}$ ) and $0.384 \pm 0.087 \mathrm{mg} / \mathrm{mL}$ (Tb concentration of $0.077 \mathrm{mg} / \mathrm{mL}$ ) on hFB. In this regard, Iram et al. (2016) showed that the presence of Tb2O3 particles had an IC50 of $0.001 \mathrm{mg} / \mathrm{mL}$ in osteosarcoma cells. This value was lower than that obtained in our work, even though the final Tb concentration in this work was lower $(0.0008 \mathrm{mg} / \mathrm{mL})$ considering the proportion in Tb203 particles. This indicates a higher toxicity of the Tb2O3 particles than those of Tb-MOF. However, contrasting results were obtained by Setyawati et al. (2013) regarding the viability of hFB in the presence of Tb-Gd2O3. The authors observed that $0.75 \mathrm{mg} / \mathrm{mL}$ of Tb-Gd2O3 $(0.228 \mathrm{mg} \mathrm{Tb} / \mathrm{mL})$ induced a $40 \%$ reduction in the viability of $\mathrm{hFB}$. Therefore, the contradictory results of the studies described above may indicate that the specific effects on cell lines could be due to the characteristics of the complexes of NMs and not due to the Tb concentration. Furthermore, it is important to highlight that studies have shown that same nanomaterial may have different toxic effects depending on the cell line (Heng et al. 2010), or even between the type of culture used like monocultures or co-cultures (Ventura et al. 2020). Accordingly, more studies must be conducted to determine the mechanisms by which NMs generate cytotoxicity, as well as to continue with the search for in vitro cell models that allow the implications in vivo to be inferred.

On the other hand, through inverted microscopy and FESEM-EDS analysis, it was determined that Tb-MOF $(1.6 \mathrm{mg} / \mathrm{mL})$ induced important changes in fibroblast morphology respect to the control. For instance, irregular prolongations and oval nuclei, (Supplementary Fig. 2) as well as a remarkable contraction of the cells, making them round (Fig. 1), decreased their adhesion capacity for the culture surface, which was confirmed when they were lifted when washing the culture plates. Similar results have also been obtained in osteosarcoma cells, dermal fibroblasts and L929 cells when exposed to Tb203 $(3.73 \times 10-4 \mathrm{mg} / \mathrm{mL})$, $\mathrm{ZnO}(0.5 \mathrm{mg} / \mathrm{mL})$ and $\mathrm{Mo}(0.1 \mathrm{mg} / \mathrm{mL})$ nanoparticles, respectively (Siddiqui et al. 2015; Iram et al. 2016; Abe et al. 2018). However, it has been proposed that morphological changes can also vary depending on the cell line and nanoparticles used (Li et al. 2012). Such losses of the specific morphological characteristics of cells have been demonstrated to be evidence of the induced toxicity of nanoparticles in cells as a stress response to the extracellular environment to which they are subjected (Iram et al. 2016; Yamaba et al. 2016). Therefore, the subtle effects of Tb-MOF on cell morphology can indirectly lead to disturbance of cell function, while severe morphological alterations, such as rounding and cell contraction, can be interpreted in terms of cell death (Zhivotovsky and Orrenius 2011).

Moreover, we showed internalization of Tb-MOF and its deposition onto the cell surface (Figs. 3,4 ). It is known when NMs are deposited on cells, they can sediment which could increase their concentration on 
the cell surface, thus facilitating uptake by cells (Cho et al. 2011) in which, in turn, might produce a decrease in cell viability depending on the dose, as well as various metabolic and morphological effects (Plascencia-Villa et al. 2012). Thus, nanoparticles can be internalized and form agglomerates (Magdolenova et al. 2012), as well as protuberances, which can lead to cell death (Berry et al. 2003; Gupta and Curtis 2004). However, the methods of absorption and biodistribution of nanoparticles depend on the size, shape, and others physicochemical properties of nanomaterials (Kunzmann et al. 2011).

On the other hand, we showed that Tb-MOF induced a change in DNMT expression, mainly affecting DNMT3A and DMT3B, by exposing hFB cells at $0.05-0.02 \mathrm{mg} / \mathrm{mL}$ (Fig. $5 \mathrm{~A}$ ). In this regard, it has been reported that exposing keratinocyte cells ( $\mathrm{HaCaT}$ ) to $\mathrm{SiO} 2$ nanoparticles leads to a reduction of DNMT1 and DNMT3A at mRNA and protein level (Gong et al. 2010). Consistent with this finding, a downregulation of DNMT1 and - 3B was also induced by $\mathrm{ZnO}$ nanoparticles $(0.05 \mathrm{mg} / \mathrm{mL})$ in human embryonic kidney cells (HEK-293) (Choudhury et al. 2017). In contrast, it appears that Ag nanoparticles are able to induce the overexpression of DNMTs in neuronal cells of the mouse (HT22) (Mytych et al. 2017). In line with this result, we detected that Tb-MOF leads to upregulating DNMT3A and decrease DNMT3B expression, conjecturing that increasing in DNMT3A could arise as an adaptive cellular response to maintain the methylation state. However, it must be considered that DNMTs expression might be dependent on the nanoparticle's specific features and the type of cell to be evaluated (Pogribna and Hammons 2021). Besides, whether Tb-MOF impairs DNA methyltransferase activity (e.g DNMT3B) or only leads to dysregulation of DNMT expression require further research.

Although there are gaps in the body of knowledge regarding the epigenetic events that happen after cells are exposed to nanomaterials, it seems that loss of function of DNMT2, a DNA methyltransferase of DNA and RNA, lead to upregulate DNMT3A and DNMT3B in foreskin fibroblast cells (Lewinska et al. 2018) and all DNMTs in mouse fibroblasts (NIH3T3) by inducing a hypermethylation of DNA and RNA (Lewinska et al. 2018). However, due to the divergent activity of DNA methyltransferases (Hervouet et al. 2018), future studies need to be carried out to determine the effect of NMs on methylation and on, in principle, genes related to cell proliferation (e.g. genes involved in p53 pathway).

On the other hand, it has been also proposed that DNMTs may be involved in the adaptive response to oxidative stress, since the exposure of human embryonic lung fibroblasts (HEF) and human fetal lung fibroblasts WI-38 to hydrogen peroxide results in increased DNMTs expression (Zhang et al. 2008; Lewinska et al. 2018). These findings are relevant because there is evidence that, in general, metallic nanoparticles can increase the formation of reactive oxygen species (ROS) in skin cells, associating it with the generation of oxidative stress, an important event that affect chromatin integrity and DNA methylation (Pogribna and Hammons 2021) considered as the main cause of toxicity of nanomaterials (Dusinska et al. 2017; Pogribna and Hammons 2021). In this aspect, it would be interesting to evaluate the levels of expression of DNMT2 in fibroblast cells exposed to nanomaterials considering the sensitivity to oxidative stress and cell proliferation that has been demonstrated in human fibroblasts exposed to this type of stress (Lewinska et al. 2018). 
On the other hand, TET family members (TET1, TET2 and TET3) catalyze the process of demethylation to maintain the correct balance of DNA methylation in the genome (Franchini et al. 2012). If well, that TET proteins have tumor-suppressor functions that are essential for maintaining genome integrity (Rasmussen and Helin 2016; Cimmino et al. 2017). The expression levels of TETs can vary among cells/organs, and their specific activities in many biological processes have not been elucidated (Delatte and Fuks 2013; Jiang et al. 2017). Here, we found that all Tb-MOF concentrations led to increase TETS expression levels (Fig. 5B). These results suggest an increase of 5-hmC levels in DNA associated with the increased expression of TET1, TET2 and TET3 genes (Fig. 5B). In line with our findings, it has been reported that $\mathrm{ZnO}$ nanoparticles induce an hypomethylation of DNA by decreasing DNA methyltransferase activity and increasing expression of TET1 and TET2 genes in HEK293 cells and human MRC5 lung fibroblast (Patil et al. 2016; Choudhury et al. 2017). Although it has been reported that there is a correlation between ROS generation and the increased expression of TETs that lead to global DNA hypomethylation (Choudhury et al. 2017), the mechanism leading to upregulation of TETs expression by TB-MOF requires to be demonstrated. Furthermore, although an increase in the expression levels of TETs has been reported, a decrease in them has also been shown, differentiated by the nanomaterial used and the model cell line (Lu et al. 2016). It indicates that further studies are warranted to clarify in greater depth the possible mechanisms governing the effects of different classes of nanometric materials, such as Tb-MOF, have had on human health.

\section{Conclusion}

Taken together, our results suggest that cells exposed to Tb-MOF show evidence of significant impact on cell behavior such as adhesion, viability, and change in the epigenetic landscape, which could lead to the development of human diseases. Clearly, more studies are needed to determine the functional consequences and potential effects on human health caused by exposure to Tb-MOF and/or nanomaterial complexes. This study presents evidence relevant to the possible damage caused by some nanomaterials, such as MOFs, when they are used without knowledge of their effects on the environment and human health.

\section{Declarations}

Ethics approval and consent to participate

Not applicable

Consent for publication

Not applicable

Availability of data and materials

Not applicable 
Competing interests

The authors declare there are no competing financial interests.

Funding

This work was supported by funds of the Consul National of Science and Technology (CONACYT) (Grant No. 284140).

Authors' contributions

Carrillo-Cocom Leydi Maribel, Juárez-Méndez Lucia and Nic-Can Geovanny Iran, carried out the experiment. Carrillo-Cocom Leydi Maribel and Nic-Can Geovanny Iran wrote the manuscript with support from Rincón Susana, Rivera-Villanueva José María and Zepeda Alejandro. Zepeda Alejandro conceived the original idea and supervised the project.

\section{References}

1. Abe Y, Fujiwara Y, Takahashi H, Matsumura Y, Sawada T, Jiang S, Nakaki R, Uchida A, Nagao N, Naito $\mathrm{M}$ et al. (2018). Histone demethylase JMJD1A coordinates acute and chronic adaptation to cold stress via thermogenic phospho-switch. Nat Commun 9: 1566. doi:10.1038/s41467-018-03868-8

2. Bashir S, Luo Z, Martinez B, Okakpu U, Liu J. 2015a. Biosafety Evaluation of Nanoscaled Porous Energy Materials. in Nanomaterials for Sustainable Energy, pp. 239-268. Oxford University Press, Washington, DC.

3. Bashir S, Wang T, Chen YP, Liu JL. 2015b. Nanomaterials Induced Cell Damage. in Oxidative Stress: Diagnostics, prevention, and therapy (eds. M Hepel, S Andreescu), pp. 431-461. Oxford University Press, Washington, DC.

4. Berry C, Wells S, Charles S, Curtis AS. (2003). Dextran and albumin derivatised iron oxide nanoparticles: influence on fibroblasts in vitro. Biomaterials 24: 4551-4557. doi:10.1016/S01429612(03)00237-0

5. Brame J, Li Q, Alvarez PJ. (2011). Nanotechnology-enabled water treatment and reuse: emerging opportunities and challenges for developing countries. Trends in Food Science \& Technology 22: 618624. doi:10.1016/j.tifs.2011.01.004

6. Brookes E, Shi Y. (2014). Diverse epigenetic mechanisms of human disease. Annu Rev Genet 48: 237268. doi:10.1146/annurev-genet-120213-092518

7. Cho EC, Zhang Q, Xia Y. (2011). The effect of sedimentation and diffusion on cellular uptake of gold nanoparticles. Nat Nanotechno/ 6: 385-391. doi:10.1038/nnano.2011.58

8. Choudhury SR, Ordaz J, Lo CL, Damayanti NP, Zhou F, Irudayaraj J. (2017). From the Cover: Zinc oxide Nanoparticles-Induced Reactive Oxygen Species Promotes Multimodal Cyto- and Epigenetic Toxicity. Toxicol Sci 156: 261-274. doi:10.1093/toxsci/kfw252 
9. Cimmino L, Dolgalev I, Wang Y, Yoshimi A, Martin GH, Wang J, Ng V, Xia B, Witkowski MT, MitchellFlack M et al. (2017). Restoration of TET2 Function Blocks Aberrant Self-Renewal and Leukemia Progression. Cel/ 170: 1079-1095 e1020. doi:10.1016/j.cell.2017.07.032

10. Dang S, Ma E, Sun ZM, Zhang H. (2012). A layer-structured Eu-MOF as a highly selective fluorescent probe for Fe3+ detection through a cation-exchange approach. Journal of Materials Chemistry 33: 16920-16926. doi:10.1039/C2JM32661B

11. De Matteis V. (2017). Exposure to Inorganic Nanoparticles: Routes of Entry, Immune Response, Biodistribution and In Vitro/In Vivo Toxicity Evaluation. Toxics 5. doi:10.3390/toxics5040029

12. Delatte B, Fuks F. (2013). TET proteins: on the frenetic hunt for new cytosine modifications. Brief Funct Genomics 12: 191-204. doi:10.1093/bfgp/elt010

13. Di W, Li J, Shirahata N, Sakka Y, Willinger MG, Pinna N. (2011). Photoluminescence, cytotoxicity and in vitro imaging of hexagonal terbium phosphate nanoparticles doped with europium. Nanoscale 3 : 1263-1269. doi:10.1039/c0nr00673d

14. Dusinska M, Tulinska J, El Yamani N, Kuricova M, Liskova A, Rollerova E, Runden-Pran E, Smolkova B. (2017). Immunotoxicity, genotoxicity and epigenetic toxicity of nanomaterials: New strategies for toxicity testing? Food Chem Toxico/ 109: 797-811. doi:10.1016/j.fct.2017.08.030

15. Fan T, Xia T, Zhang Q, Cui Y, Yang Y, Qian G. (2018). A porous and luminescent metal-organic framework containing triazine group for sensing and imaging of Zn2+. Microporous and Mesoporous Materials 266: 1-6. doi:10.1016/j.micromeso.2018.02.050

16. Feoktistova M, Geserick P, Leverkus M. (2016). Crystal Violet Assay for Determining Viability of Cultured Cells. Cold Spring Harb Protoc 2016: pdb prot087379. doi:10.1101/pdb.prot087379

17. Franchi LP, Manshian BB, de Souza TA, Soenen SJ, Matsubara EY, Rosolen JM, Takahashi CS. (2015). Cyto- and genotoxic effects of metallic nanoparticles in untransformed human fibroblast. Toxicol In Vitro 29: 1319-1331. doi:10.1016/j.tiv.2015.05.010

18. Franchini DM, Schmitz KM, Petersen-Mahrt SK. (2012). 5-Methylcytosine DNA demethylation: more than losing a methyl group. Annu Rev Genet 46: 419-441. doi:10.1146/annurev-genet-110711155451

19. Gangu KK, Maddila S, Mukkamala SB, Jonnalgadda SB. (2016). A review on contemporary MetalOrganic Framework materials. Inorganica Chimica Acta 446: 61-74. doi:10.1016/j.ica.2016.02.062

20. Gong C, Tao G, Yang L, Liu J, Liu Q, Zhuang Z. (2010). SiO(2) nanoparticles induce global genomic hypomethylation in HaCaT cells. Biochem Biophys Res Commun 397: 397-400. doi:10.1016/j.bbrc.2010.05.076

21. Gupta AK, Curtis AS. (2004). Lactoferrin and ceruloplasmin derivatized superparamagnetic iron oxide nanoparticles for targeting cell surface receptors. Biomaterials 25: 3029-3040. doi:10.1016/j.biomaterials.2003.09.095

22. Heng BC, Das GK, Zhao X, Ma LL, Tan TT, Ng KW, Loo JS. (2010). Comparative cytotoxicity evaluation of lanthanide nanomaterials on mouse and human cell lines with metabolic and DNAquantification assays. Biointerphases 5: FA88-97. doi:10.1116/1.3494617 
23. Hervouet E, Peixoto P, Delage-Mourroux R, Boyer-Guittaut M, Cartron PF. (2018). Specific or not specific recruitment of DNMTs for DNA methylation, an epigenetic dilemma. Clin Epigenetics 10: 17. doi:10.1186/s13148-018-0450-y

24. Huang WH, Ren J, Yang YH, Li XM, Wang Q, Jiang N, Yu JQ, Wang F, Zhang J. (2019). Water-Stable Metal-Organic Frameworks with Selective Sensing on Fe(3+) and Nitroaromatic Explosives, and Stimuli-Responsive Luminescence on Lanthanide Encapsulation. Inorg Chem 58: 1481-1491. doi:10.1021/acs.inorgchem.8b02994

25. Iram S, Khan S, Ansary AA, Arshad M, Siddiqui S, Ahmad E, Khan RH, Khan MS. (2016). Biogenic terbium oxide nanoparticles as the vanguard against osteosarcoma. Spectrochim Acta A Mol Biomol Spectrosc 168: 123-131. doi:10.1016/j.saa.2016.05.053

26. Jiang D, Wei S, Chen F, Zhang Y, Li J. (2017). TET3-mediated DNA oxidation promotes ATRdependent DNA damage response. Embo Rep 18: 781-796. doi:10.15252/embr.201643179

27. Kunzmann A, Andersson B, Thurnherr T, Krug H, Scheynius A, Fadeel B. (2011). Toxicology of engineered nanomaterials: focus on biocompatibility, biodistribution and biodegradation. Biochim Biophys Acta 1810: 361-373. doi:10.1016/j.bbagen.2010.04.007

28. Lewinska A, Adamczyk-Grochala J, Kwasniewicz E, Deregowska A, Semik E, Zabek T, Wnuk M. (2018). Reduced levels of methyltransferase DNMT2 sensitize human fibroblasts to oxidative stress and DNA damage that is accompanied by changes in proliferation-related miRNA expression. Redox Biol 14: 20-34. doi:10.1016/j.redox.2017.08.012

29. Li L, Mak KY, Shi J, Koon HK, Leung CH, Wong CM, Leung CW, Mak CS, Chan NM, Zhong W et al. (2012). Comparative in vitro cytotoxicity study on uncoated magnetic nanoparticles: effects on cell viability, cell morphology, and cellular uptake. J Nanosci Nanotechno/ 12: 9010-9017. doi:10.1166/jnn.2012.6755

30. Lin W, Hu Q, Yu J, Jiang K, Yang Y, Xiang S, Cui Y, Yang Y, Wang Z, Qian G. (2016). Low Cytotoxic Metal-Organic Frameworks as Temperature-Responsive Drug Carriers. Chempluschem 81: 804-810. doi:10.1002/cplu.201600142

31. Liu W, Dai X, Bai Z, Wang Y, Yang Z, Zhang L, Xu L, Chen L, Li Y, Gui D et al. (2017). Highly Sensitive and Selective Uranium Detection in Natural Water Systems Using a Luminescent Mesoporous MetalOrganic Framework Equipped with Abundant Lewis Basic Sites: A Combined Batch, X-ray Absorption Spectroscopy, and First Principles Simulation Investigation. Environ Sci Techno/ 51: 3911-3921. doi:10.1021/acs.est.6b06305

32. Livak KJ, Schmittgen TD. (2001). Analysis of relative gene expression data using real-time quantitative PCR and the 2(-Delta Delta C(T)) Method. Methods 25: 402-408. doi:10.1006/meth.2001.1262

33. Lu X, Miousse IR, Pirela SV, Melnyk S, Koturbash I, Demokritou P. (2016). Short-term exposure to engineered nanomaterials affects cellular epigenome. Nanotoxicology 10: 140-150. doi:10.3109/17435390.2015.1025115 
34. Lunstroot K, Nockemann P, Van Hecke K, Van Meervelt L, Gorller-Walrand C, Binnemans K, Driesen K. (2009). Visible and near-infrared emission by samarium(III)-containing ionic liquid mixtures. Inorg Chem 48: 3018-3026. doi:10.1021/ic8020782

35. Magdolenova Z, Bilanicova D, Pojana G, Fjellsbo LM, Hudecova A, Hasplova K, Marcomini A, Dusinska M. (2012). Impact of agglomeration and different dispersions of titanium dioxide nanoparticles on the human related in vitro cytotoxicity and genotoxicity. J Environ Monit 14: 455464. doi:10.1039/c2em10746e

36. Mosmann T. (1983). Rapid colorimetric assay for cellular growth and survival: application to proliferation and cytotoxicity assays. J Immunol Methods 65: 55-63. doi:10.1016/00221759(83)90303-4

37. Mytych J, Zebrowski J, Lewinska A, Wnuk M. (2017). Prolonged Effects of Silver Nanoparticles on p53/p21 Pathway-Mediated Proliferation, DNA Damage Response, and Methylation Parameters in HT22 Hippocampal Neuronal Cells. Mol Neurobio/ 54: 1285-1300. doi:10.1007/s12035-016-9688-6

38. Pal S, Bharadwaj PK. (2016). A Luminescent Terbium MOF Containing Hydroxyl Groups Exhibits Selective Sensing of Nitroaromatic Compounds and Fe(III) lons. Crystal Growth \& Desing 16: 58525858. doi:10.1021/acs.cgd.6b00930

39. Patil NA, Gade WN, Deobagkar DD. (2016). Epigenetic modulation upon exposure of lung fibroblasts to TiO2 and ZnO nanoparticles: alterations in DNA methylation. Int J Nanomedicine 11: 4509-4519. doi:10.2147/IJN.S110390

40. Plascencia-Villa G, Starr CR, Armstrong LS, Ponce A, Jose-Yacaman M. (2012). Imaging interactions of metal oxide nanoparticles with macrophage cells by ultra-high resolution scanning electron microscopy techniques. Integr Biol (Camb) 4: 1358-1366. doi:10.1039/c2ib20172k

41. Plongthongkum N, Diep DH, Zhang K. (2014). Advances in the profiling of DNA modifications: cytosine methylation and beyond. Nat Rev Genet 15: 647-661. doi:10.1038/nrg3772

42. Pogribna M, Hammons G. (2021). Epigenetic Effects of Nanomaterials and Nanoparticles. $J$ Nanobiotechnology 19: 2. doi:10.1186/s12951-020-00740-0

43. Rasmussen KD, Helin K. (2016). Role of TET enzymes in DNA methylation, development, and cancer. Genes Dev 30: 733-750. doi:10.1101/gad.276568.115

44. Rinaldi L, Benitah SA. (2015). Epigenetic regulation of adult stem cell function. FEBS J 282: 15891604. doi:10.1111/febs. 12946

45. Sajid M. (2016). Toxicity of nanoscale metal organic frameworks: a perspective. Environ Sci Pollut Res Int 23: 14805-14807. doi:10.1007/s11356-016-7053-y

46. Setyawati MI, Khoo PK, Eng BH, Xiong S, Zhao X, Das GK, Tan TT, Loo JS, Leong DT, Ng KW. (2013). Cytotoxic and genotoxic characterization of titanium dioxide, gadolinium oxide, and poly(lactic-coglycolic acid) nanoparticles in human fibroblasts. J Biomed Mater Res A 101: 633-640. doi:10.1002/jbm.a.34363

47. Sharma V, Anderson D, Dhawan A. (2012). Zinc oxide nanoparticles induce oxidative DNA damage and ROS-triggered mitochondria mediated apoptosis in human liver cells (HepG2). Apoptosis 17: 
48. Siddiqui MA, Saquib Q, Ahamed M, Farshori NN, Ahmad J, Wahab R, Khan ST, Alhadlaq HA, Musarrat J, Al-Khedhairy AA et al. (2015). Molybdenum nanoparticles-induced cytotoxicity, oxidative stress, G2/M arrest, and DNA damage in mouse skin fibroblast cells (L929). Colloids Surf B Biointerfaces 125: 73-81. doi:10.1016/j.colsurfb.2014.11.014

49. Ventura C, Pereira JFS, Matos P, Marques B, Jordan P, Sousa-Uva A, Silva MJ. (2020). Cytotoxicity and genotoxicity of MWCNT-7 and crocidolite: assessment in alveolar epithelial cells versus their coculture with monocyte-derived macrophages. Nanotoxicology 14: 479-503. doi:10.1080/17435390.2019.1695975

50. Viveros-Andrade AG, Colorado-Peralta R, Flores-Alamo M, Castillo-Blum SE, Durán-Hernández J, Rivera JM. (2017). Solvothermal synthesis and spectroscopic characterization of three lanthanide complexes with high luminescent properties [H 2 NMe 2 ] 3 [ $\mathrm{Ln}(\mathrm{III})(2,6$-pyridinedicarboxylate) 3 ] ( $\mathrm{Ln}=$ $\mathrm{Sm}, \mathrm{Eu}, \mathrm{Tb})$ : In the presence of 4,4'-Bipyridyl. Journal of Molecular Structure 1145: 10-17. doi:10.1016/j.molstruc.2017.05.055

51. Wang F, Gao F, Lan M, Yuan H, Huang Y, Liu J. (2009). Oxidative stress contributes to silica nanoparticle-induced cytotoxicity in human embryonic kidney cells. Toxicol In Vitro 23: 808-815. doi:10.1016/j.tiv.2009.04.009

52. Wang J, Sun W, Chang S, Liu H, Zhang G, Wang Y, Liu Z. (2015). A terbium metal-organic framework with stable luminescent emission in a wide $\mathrm{pH}$ range that acts as a quantitative detection material for nitroaromatics. RSC Advances 5: 48574-48579. doi:10.1039/c5ra06308f

53. Wang M, Lai X, Shao L, Li L. (2018). Evaluation of immunoresponses and cytotoxicity from skin exposure to metallic nanoparticles. Int J Nanomedicine 13: 4445-4459. doi:10.2147/IJN.S170745

54. Wuttke S, Zimpel A, Bein T, Braig S, Stoiber K, Vollmar A, Muller D, Haastert-Talini K, Schaeske J, Stiesch M et al. (2017). Validating Metal-Organic Framework Nanoparticles for Their Nanosafety in Diverse Biomedical Applications. Adv Healthc Mater 6. doi:10.1002/adhm.201600818

55. Yamaba H, Haba M, Kunita M, Sakaida T, Tanaka H, Yashiro Y, Nakata S. (2016). Morphological change of skin fibroblasts induced by UV Irradiation is involved in photoaging. Exp Dermato/ 25 Suppl 3: 45-51. doi:10.1111/exd.13084

56. Zhang W, Ji W, Yang J, Yang L, Chen W, Zhuang Z. (2008). Comparison of global DNA methylation profiles in replicative versus premature senescence. Life Sci 83: 475-480. doi:10.1016/j.Ifs.2008.07.015

57. Zhao B, Chen XY, Chen Z, Shi W, Cheng P, Yan SP, Liao DZ. (2009). A porous 3D heterometal-organic framework containing both lanthanide and high-spin Fe(ii) ions. Chem Commun (Camb): 3113-3115. doi:10.1039/b821496d

58. Zhivotovsky B, Orrenius S. (2011). Calcium and cell death mechanisms: a perspective from the cell death community. Cell Calcium 50: 211-221. doi:10.1016/j.ceca.2011.03.003

59. Zhou HC, Long JR, Yaghi OM. (2012). Introduction to metal-organic frameworks. Chem Rev 112: 673674. doi:10.1021/cr300014x 
60. Zhou ZY, Han YH, Xing XS, Du SW. (2016). Microporous Lanthanide Metal-Organic Frameworks with Multiple 1D Channels: Tunable Colors, White-Light Emission, and Luminescent Sensing for Iron(II) and Iron(III). Chempluschem 81: 798-803. doi:10.1002/cplu.201600141

\section{Scheme}

Scheme 1 is available in Supplemental Files section.

\section{Figures}

\section{Figure 1}

Cell density assay of culture human fibroblasts (hFB) cells exposed to different concentrations of TbMOF. hFB cells exposed or not (control) to Tb-MOF were stained with Crystal violet after 48 hours treatment. Magnification 10X.

\section{Figure 2}

Cell density of human fibroblasts cells exposed to Tb-MOF. (a) Crystal violet, (b): MTT. The cell density was calculated with respect to the density of the control (cells incubated without nanomaterials). Cells with DMSO (positive control) detached with the washes so there was no staining. The error bars indicate the standard deviation $(n=9)$. * Indicates significant differences from control $(p<0.05)$ calculated by Tukey 's HSD post-hoc test.

\section{Figure 3}

Representative FESEM images of human fibroblasts cells exposed to Tb-MOF. (a) untreated cell (control), (b) cell with $0.05 \mathrm{mg} / \mathrm{mL}$ of nanomaterial that was deposited or internalized in the cell (white arrows), (c) cell treated with $1.6 \mathrm{mg} / \mathrm{mL}$ of MOF which was deposited on its surface, (d) linear energy dispersive spectroscopy analysis of cells treated with $0.05 \mathrm{mg} / \mathrm{mL}$ of nanomaterial, lines represent - Carbon, -Oxygen, - Terbium and -- section analyzed. 


\section{Figure 4}

Photoluminescent properties of Tb-MOF in human fibroblast cells. Confocal microscopy analysis of human fibroblast cells exposed or not (control) at two concentrations of Tb-MOF to determine its internalization into fibroblasts. Photoluminescent properties of Tb-MOF were detected by using excitation wavelength of $330 \mathrm{~nm}$ and $490 \mathrm{~nm}$. Red arrows indicate the presence of Tb-MOF.

\section{Figure 5}

mRNA expression levels of DNA methyltransferases and demethylases in hFB cell induced by Tb-MOF. (a) DNA methyltransferases (DNMT1, DNMT3a, DNMT3b), (b) Ten eleven translocation family members (TET1, TET2, TET3). Human fibroblast cells were treated for $48 \mathrm{~h}$ with Tb-MOF and the mRNA of three independent assays were used to qPCR analysis. Data shows gene expression normalized to housekeeping gene (18S rRNA). The values above the brackets indicate the p-value with statistical difference.

\section{Supplementary Files}

This is a list of supplementary files associated with this preprint. Click to download.

- FigS1.tiff

- FigS2.tif

- TablesS1.pdf

- Scheme1ESPR.tiff 